\title{
Factors Influencing the Use of Second-Generation Antipsychotics in Children with Psychosis
}

\author{
Sujith Ramachandran, MS, PhD Candidate; Benjamin F. Banahan III, PhD; John P. Bentley, PhD;
} Donna S. West-Strum, PhD; and Amit S. Patel, PhD

\begin{abstract}
BACKGROUND: In 2011, the U.S. Department of Health and Human Services sent a letter to state Medicaid directors explaining the need for oversight of psychiatric prescriptions for children with mental health disorders. The National Committee for Quality Alliance proposed 3 quality measures for rating managed care organizations (MCOs) that involve use of second-generation or atypical antipsychotics in children. In order to ensure appropriate use and to effectively manage the use of second-generation antipsychotics in children, MCOs need to better understand the factors that influence medication treatment decisions for children.
\end{abstract}

OBJECTIVES: To (a) determine how patient-level and physician-level factors influence decisions to prescribe second-generation antipsychotics to children (aged under 18 years) diagnosed with psychosis and (b) evaluate how the influence of these factors may differ between primary care providers and psychiatrists.

METHODS: This study employed a cross-sectional survey of 193 primary care providers and psychiatrists. A web-based patient simulation survey using a fractional factorial design was administered via a commercial vendor. Respondents were presented with simulated patient profiles described by various levels of factors considered to be essential to decision making. Respondents were asked to make treatment recommendations for each profile evaluated. In addition to treatment recommendations, demographics and beliefs about products were measured. Modified Poisson regression accounting for multilevel data was used to identify the factors that significantly affect treatment recommendations.

RESULTS: Psychiatrists were more likely to recommend second-generation antipsychotics than primary care practitioners (unadjusted $\mathrm{RR}=1.36,95 \%$ $\mathrm{Cl}=1.23-1.51$ ). Social factors such as foster status or parental concern were not found to be significant predictors of prescribing second-generation antipsychotics. The percentage of a provider's patients using secondgeneration antipsychotics ( $\mathrm{RR}=1.002,95 \% \mathrm{Cl}=1.0002-1.003)$, patient age (aged 4 years: $\mathrm{RR}=0.75,95 \% \mathrm{Cl}=0.68-0.84$; aged 10 years: $\mathrm{RR}=0.94$, $95 \% \mathrm{Cl}=0.91-0.99$; reference group: aged 15 years), and patient disease severity (severe: $R R=1.11,95 \% \mathrm{Cl}=1.04-1.18$; moderate: $R R=1.10,95 \%$ $\mathrm{Cl}=1.05-1.17$; reference group: mild) significantly predicted prescription behavior among primary care providers and psychiatrists. Primary care providers were about twice as likely to recommend antipsychotics if they believed the use of antipsychotics was a labeled indication ( $R R=2.16,95 \%$ $\mathrm{Cl}=1.56-2.98)$ or a medically accepted use $(\mathrm{RR}=1.88,95 \% \mathrm{Cl}=1.33-2.67)$, when compared with physicians who believed there was no evidence available. This effect was not significant among psychiatrists. Primary care providers, but not psychiatrists, were also significantly influenced by patient white blood cell (WBC) count. Patients with healthy WBC counts were 1.11 times as likely $(95 \% \mathrm{Cl}=1.05-1.17)$ to receive antipsychotics from primary care providers compared with those with low WBC count. Patient body mass index (BMI) was not found to significantly influence prescribing behavior. Nearly $50 \%$ of patients did not receive recommendations for psychosocial care. Primary care providers recommended antipsychotic polypharmacy in $23 \%$ of the patient profiles, while psychiatrists did so in $42 \%$ of the profiles.
CONCLUSIONS: This study provides valuable insight into physicianprescribing practices for antipsychotics. The lack of significance of foster status and parental concern, after controlling for other factors, shows that physicians base their decisions on clinical factors more than social factors. Results for patient BMI and frequency of recommendations of polypharmacy are concerning. The general lack of awareness of evidence supporting use of antipsychotics is also highly concerning. The effects of patient BMI, beliefs about evidence supporting use, and prescribing practices with regard to psychosocial care and antipsychotic polypharmacy provide actionable results for managed care programs looking to improve their quality metrics. The results of this study further demonstrate the need for the immediate implementation of the various proposed quality metrics in this area and for new practice guidelines to raise the current standard of care.

J Manag Care Spec Pharm. 2016;22(8):948-57

Copyright $\odot 2016$, Academy of Managed Care Pharmacy. All rights reserved.

\section{What is already known about this subject}

The use of second-generation antipsychotics in children is steadily increasing for several conditions, including psychosis The introduction of quality metrics and attention from the Centers for Medicare \& Medicaid Services have highlighted the importance of the increased use of antipsychotics in children. Foster children are known to receive a disproportionately high percentage of second-generation antipsychotics when compared with other children

\section{What this study adds}

This study showed that factors such as foster status, parental concern, and patient body mass index do not influence physician decision making after controlling for other factors.

Evidence was found for antipsychotic polypharmacy and lack of evidence-based prescribing behavior, which suggests a need for new treatment guidelines and improved physician education.

T he use of second-generation or atypical antipsychotics in children and adolescents has increased substantially over the past few years. ${ }^{1}$ Although there is limited evidence of the efficacy of these drugs in children, they are being prescribed for children to treat several different conditions. Up to $10 \%$ of antipsychotics used in children are prescribed for psychosis. ${ }^{1,2}$ Existing studies in this area point toward a range 
of potentially serious adverse events such as weight gain, diabetes, hypertension, metabolic and endocrine abnormalities, hyperprolactinemia, and dyslipidemia in the short term and several other unknown long-term effects. ${ }^{3-6}$

With increasing safety concerns and budgetary constraints, payers such as Medicaid have sought to better understand the use of these drugs in children., ${ }^{7,8}$ In 2011, the U.S. Department of Health and Human Services sent a letter to state Medicaid directors making them aware of the growing problem of antipsychotic use among foster children., ${ }^{910}$ The National Committee for Quality Alliance has proposed a set of quality measures related to use of antipsychotics in children in the Healthcare Effectiveness Data and Information Set (HEDIS). These measures include use of first-line psychosocial care, metabolic monitoring of children who are prescribed antipsychotics, and antipsychotic polypharmacy in children. ${ }^{11}$ An increasing number of payers, including state Medicaid programs, are considering using these measures to rate managed care programs as they transition to a quality-based payment strategy. ${ }^{12,13}$ It is imperative that managed care programs obtain a better understanding of the decisions behind antipsychotic prescriptions to help formulate strategies to improve their performance on these quality measures.

Antipsychotic prescription decisions can be influenced by factors related to the patient or the provider. Patient characteristics, such as patient age, gender, body mass index (BMI), insurance, foster status, parental consent, and white blood cell (WBC) count, ${ }^{1,3-6,9}$ and physician characteristics, such as type and size of practice, specialization, and evidence supporting use, ${ }^{14-16}$ have been shown to influence the decision to prescribe second-generation antipsychotics to children. Although some of these factors, such as age, gender, insurance, foster status, and physician specialization, can be examined in administrative claims data, others are generally not available, necessitating the collection of primary data.

The purpose of this study was to (a) determine how patientlevel factors, such as age, race, sex, foster status, and concern about consent from parent/guardian, influence physician decisions to prescribe second-generation antipsychotics in children with psychosis; (b) determine how physician characteristics, such as specialization, mental health patient volume, and beliefs about drugs, influence physician decisions to prescribe second-generation antipsychotics in children with psychosis; and (c) evaluate whether the influence of patient-level factors and physician characteristics on physician decisions was different for primary care providers and psychiatrists.

\section{Methods}

\section{Study Design and Data Collection}

This study employed a cross-sectional survey using separate convenience samples of primary care providers and psychiatrists. General psychiatrists and child psychiatrists were classified as psychiatrists, and family medicine, internal medicine, and general practice physicians and pediatricians were classified as primary care providers. The study sample was obtained through a national physician panel maintained by Reckner Healthcare, ${ }^{17}$ a commercial vendor, and data were collected over a 7-week period leading up to November 1, 2013. The physician panel was compiled using a combination of random dialing, purchased samples, and referrals from across the country. Physicians were required to go through a short set of screening questions to make sure they met the inclusion criteria for the study. To be eligible for the study, physicians had to be engaged in full-time active practice for at least 2 years after residency and had to spend a considerable portion of their time in the outpatient care setting (50\% for primary care providers and $25 \%$ for psychiatrists). Physicians were eligible for the study if their practices included children diagnosed with psychosis and prescribed second-generation antipsychotics.

\section{Survey Design}

The survey included a short screener with demographics, a patient simulation section, and a final section that measured physician beliefs and practice attitudes. In the patient simulation section, each physician was presented with a set of patient cases/profiles with information about patient demographics, symptoms, clinical parameters, and other relevant information. Each profile presented a patient displaying symptoms of psychosis of varying severity. For the purpose of this study, psychosis was defined as having uncontrollable agitation, auditory hallucinations and lack of age-appropriate grooming in varying frequencies, depending on the severity of the disease. Psychosis was chosen because it could be represented in a concise profile, while still being broad enough to capture several indications for which second-generation antipsychotics are popularly used. After reviewing each patient profile, the respondents selected a treatment plan for the patient from an exhaustive list of treatment options. The information presented in each profile was carefully constructed from current literature and qualitative interviews to include variables that were expected to be relevant to decision making., ${ }^{1,-6,9,14-16}$ Six oneon-one interviews were conducted with psychiatrists, pediatricians, and mental health pharmacists to finalize the patient attributes and survey questions and test the drafted profiles. The list of variables that were present in the profiles and their various levels are presented in Table 1 .

A fractional factorial design was used to determine a combination of various levels of these patient attributes that would support statistical analysis of the effect of each attribute independently. Thirty patient profiles were created using the combination of variables listed (see the Appendix for a sample patient profile, available in online article). These 30 profiles were grouped into 3 subsets of 10 profiles each that were balanced with respect to the hypothesized major drivers of 


\begin{tabular}{|c|c|c|c|c|}
\hline \multirow[b]{2}{*}{ Variable Name } & \multirow[b]{2}{*}{ Variable Description } & \multicolumn{3}{|c|}{ Variable Levels } \\
\hline & & 0 & 1 & 2 \\
\hline Severity & Disease severity & Mild & Moderate & Severe \\
\hline Adherence & Risk for nonadherence & Absent & Present & - \\
\hline WBC & WBC count & Low & Normal & - \\
\hline ANC & ANC & Low & Normal & - \\
\hline Alcohol & Alcohol/substance abuse & No & Yes & - \\
\hline BMI & BMI & Underweight & Normal & Overweight \\
\hline Sex & Sex & Male & Female & - \\
\hline Race & Race & Caucasian & Black & - \\
\hline Age & Age & $<5$ years & $6-12$ years & $13-17$ years \\
\hline Puberty & Puberty & No & Yes & - \\
\hline Foster & Foster status & Nonfoster & Foster & - \\
\hline Diabetes & Type 2 diabetes mellitus & No & Yes & - \\
\hline Consent & Concern about consent & None & Medium & High \\
\hline
\end{tabular}

Note: Each profile was constructed as a combination of these 13 variables at one of the possible levels. For a sample patient profile, see the Appendix (available in online article).

$A N C=$ absolute neutrophil count; $B M I=$ body mass index; $W B C=$ white blood cell .

use. Such methodology has been used by other researchers. ${ }^{18}$ Each physician respondent was shown 1 subset of 10 profiles in a randomized order. Using balanced subsets instead of a randomly selected group of 10 profiles helped ensure that respondents were exposed to an equal distribution of all major predicted factors.

The survey also contained the Evidence-Based Practice Attitude Scale (EBPAS) to assess physician attitudes toward adopting evidence-based practices (EBP). The EBPAS was developed and validated in a behavioral health provider population and contains 4 subscales: (1) Appeal of EBPs, (2) Requirements for the use of EBPs, (3) Openness to innovation, and (4) Divergence of EBP with usual practice (perceived). ${ }^{19,20}$ The EBPAS was administered after the patient profiles in order to avoid any response bias. Physician background, practice characteristics, and beliefs about evidence supporting use of second-generation antipsychotics in children with psychosis were also measured. Physician belief about evidence concerning use of second-generation antipsychotics in children with psychosis was measured by asking respondents their beliefs about the level of evidence that existed for use of 11 secondgeneration antipsychotics for 3 age categories (5 years or under, 6-12 years, and 13-17 years) presented in the patient profiles. The level of evidence categories were "labeled indication," "medically accepted use but not a labeled indication," or "no evidence supporting use." "Medically accepted use" was defined in the survey as a case where the antipsychotic drug does not have an approved indication by the U.S. Food and Drug Administration, but it has considerable evidence supporting use. Respondents could also indicate that they "don't know." The maximum level of evidence found for any second-generation antipsychotic was used for the corresponding age group. Approval for this study was obtained from the University of Mississippi's Institutional Review Board before data collection.

\section{Data Analysis}

The primary outcome variable for this analysis was whether a second-generation antipsychotic was selected as a treatment option for each patient profile presented to respondents. Each physician responded to 10 treatment profiles, creating a multilevel (or hierarchical) data structure. To assess predictors of the use of second-generation antipsychotics, an extension of a modified Poisson regression model (using a log link and a Poisson distribution) was used to handle a multilevel data structure for binary data. ${ }^{21}$ An exchangeable correlation structure was used in estimating robust standard errors. Such a model results in exponentiated coefficients that can be interpreted as risk ratios. ${ }^{21}$ Model building was done in multiple steps because of the somewhat small sample size at the physician level $(\mathrm{N}=193) .{ }^{22}$ Potential physician and patient factors were tested in separate models for the primary care providers and psychiatrists. Factors found to be significant $(P \leq 0.1)$ in either of these multivariable models were then introduced into the final model, which included both specialties and tested for interactions between physician specialty and the predictors. The inclusion of interactions assessed whether each predictor variable was differently associated with the use of second-generation antipsychotics for psychiatrists relative to primary care providers. For reasons of parsimony, nonsignificant interactions $(P>0.05)$ were dropped, and a common effect for psychiatrists and primary care providers was estimated for the variable of interest. IBM SPSS (SPSS, Chicago, IL) was 


\section{FIGURE 1 Sample Selection Flow Chart}

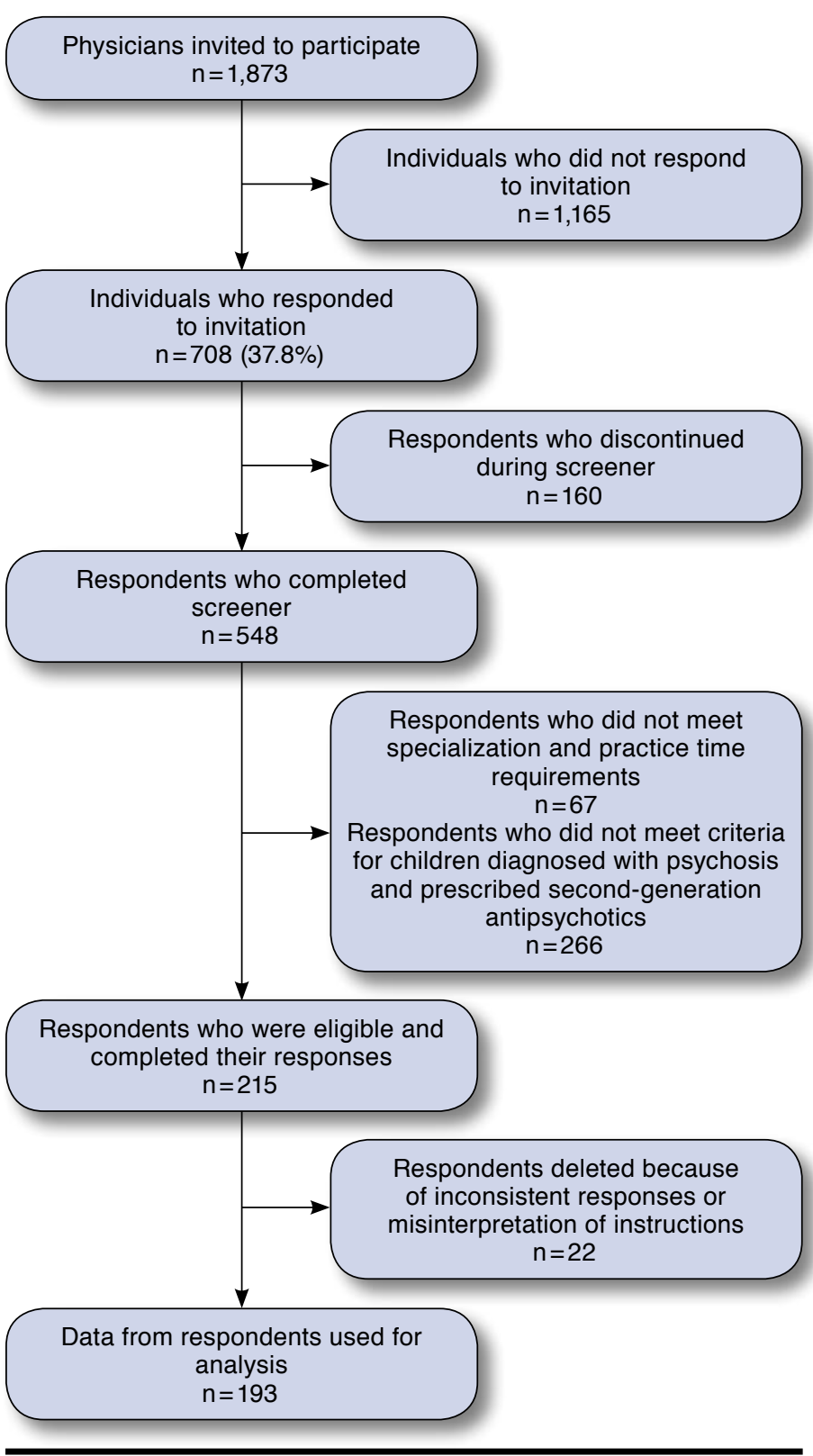

used for data analysis; the GENLIN procedure in SPSS with the repeated subcommand was used for the modified Poisson regression models.

\section{Results}

The contracted vendor invited 1,873 physicians to participate. After eliminating incomplete responses and respondents who were screened out, 215 completed surveys were collected (Figure 1). The median time to complete the survey, including those who were excluded after the screener, was about 19 minutes. A total of 193 respondents, or 1,930 $(193 \times 10)$ unique physician-patient combinations, were used in the analyses after deleting 22 respondents who showed response patterns that indicated lack of consistency in responding or a misinterpretation of survey instructions. Summaries of respondent demographics, beliefs, and practice characteristics are provided in Tables 2 and 3. The final dataset used for analysis contained 129 respondents classified as primary care providers and 64 classified as psychiatrists.

\section{Respondent Characteristics}

Compared with primary care providers, psychiatrists were significantly older, spent more years in active practice, had lower patient volume in a typical week, and had a higher percentage of patients who were foster children (Table 2). In line with expectations, primary care providers spent a significantly greater proportion of their time in outpatient care (92\% vs $80 \%$ for psychiatrists). A substantial proportion of respondents indicated that they did not know the level of evidence available for use of second-generation antipsychotics in children with psychosis (Table 2). Despite this, a substantial proportion of profiles were recommended second-generation antipsychotics.

\section{Prescribing Patterns}

Across all physicians and patient profiles, 1,374 (71\%) patient profiles were recommended treatment with second-generation antipsychotics. Primary care providers were significantly more likely to refer their patients to another provider and less likely to prescribe second-generation antipsychotics or psychosocial therapy (Table 3).

\section{Factors Influencing Prescribing Behavior}

Modified Poisson regression models were used to identify factors that influence the use of second-generation antipsychotics. Overall, psychiatrists were more likely to recommend second-generation antipsychotics than primary care providers (unadjusted risk ratio $[\mathrm{RR}]=1.36 ; 95 \%$ confidence interval $[\mathrm{CI}]=1.23-1.51$ ). The percentage of a provider's patients using second-generation antipsychotics, patient disease severity, and patient age significantly predicted prescription behavior among primary care providers and psychiatrists (i.e., significant common effect and no significant interaction between these variables and physician specialty; Table 4). Primary care providers and psychiatrists differed significantly in their prescribing behaviors, with changes in patient WBC count and beliefs about evidence supporting use of second-generation antipsychotics.

The percentage of patient population in a provider's clinical practice using second-generation antipsychotics ( $R R=1.002$; $95 \% \mathrm{CI}=1.0002-1.003)$ was found to significantly predict prescribing behavior in the simulation experiment. Patients with a severe indication were $1.11(95 \% \mathrm{CI}=1.04-1.18)$ times 


\begin{tabular}{|c|c|c|c|c|c|}
\hline \multirow[b]{3}{*}{ Variable $^{a}$} & \multicolumn{4}{|c|}{ Physician Specialty } & \multirow[b]{3}{*}{$P$ Value } \\
\hline & \multirow{2}{*}{\multicolumn{2}{|c|}{$\begin{array}{c}\text { Primary Care Provider } \\
(\mathrm{n}=129)\end{array}$}} & \multicolumn{2}{|c|}{$\begin{array}{c}\text { Psychiatrist } \\
(n=64)\end{array}$} & \\
\hline & & & & (n) & \\
\hline Females & 17.1 & $(22)$ & 17.2 & (11) & 0.982 \\
\hline \multicolumn{5}{|l|}{ Race } & \multirow[t]{7}{*}{0.522} \\
\hline Caucasians & 62.0 & $(80)$ & 65.6 & $(42)$ & \\
\hline Asian Americans & 27.9 & $(36)$ & 25.0 & $(16)$ & \\
\hline African Americans & 1.6 & (2) & 0 & $(0)$ & \\
\hline Native Hawaiians & 0.1 & (1) & 0 & (0) & \\
\hline Hispanics & 2.3 & (3) & 0 & (0) & \\
\hline Others & 5.4 & (7) & 9.4 & (6) & \\
\hline \multicolumn{5}{|c|}{ Physician belief about evidence for use of second-generation antipsychotics in children aged 5 years and under } & \multirow[t]{5}{*}{0.152} \\
\hline Don't know & 26.4 & $(34)$ & 15.6 & (10) & \\
\hline No evidence & 13.2 & $(17)$ & 21.9 & $(14)$ & \\
\hline Medically accepted use & 34.9 & $(45)$ & 42.2 & $(27)$ & \\
\hline Labeled indication & 25.6 & (33) & 20.3 & (13) & \\
\hline \multicolumn{5}{|c|}{ Physician belief about evidence for use of second-generation antipsychotics in children aged between 6 and 12 years } & \multirow[t]{5}{*}{0.068} \\
\hline Don't know & 18.6 & $(24)$ & 9.4 & (6) & \\
\hline No evidence & 6.2 & $(8)$ & 9.4 & (6) & \\
\hline Medically accepted use & 37.2 & $(48)$ & 26.6 & (17) & \\
\hline Labeled indication & 38.0 & $(49)$ & 54.7 & $(35)$ & \\
\hline \multicolumn{5}{|c|}{ Physician belief about evidence for use of second-generation antipsychotics in children aged between 13 and 17 years } & \multirow[t]{5}{*}{0.185} \\
\hline Don't know & 11.6 & $(15)$ & 4.7 & (3) & \\
\hline No evidence & 1.5 & $(2)$ & 3.1 & $(2)$ & \\
\hline Medically accepted use & 27.9 & $(36)$ & 20.3 & (13) & \\
\hline Labeled indication & 58.9 & $(76)$ & 71.9 & $(46)$ & \\
\hline \multicolumn{6}{|l|}{ Evidence-Based Practice Attitude Scale (EBPAS), ${ }^{b}$ mean $[ \pm$ SD] } \\
\hline Requirement & 1.8 & [1.1] & 1.9 & [1.1] & 0.572 \\
\hline Appeal & 2.5 & {$[0.8]$} & 2.7 & {$[0.6]$} & 0.065 \\
\hline Openness & 2.1 & [0.9] & 2.5 & {$[0.8]$} & 0.002 \\
\hline Divergence & 2.4 & [0.9] & 2.3 & {$[0.9]$} & 0.400 \\
\hline Total & 2.2 & {$[0.5]$} & 2.3 & {$[0.5]$} & 0.048 \\
\hline Age, mean $[ \pm S D]$ & 50.3 & {$[8.0]$} & 54.2 & {$[8.8]$} & 0.002 \\
\hline Years in practice, mean $[ \pm S D]$ & 18.0 & [6.9] & 20.2 & {$[7.0]$} & 0.042 \\
\hline Patient volume per week, ${ }^{\mathrm{c}}$ mean $[ \pm \mathrm{SD}]$ & 174.5 & 22.6] & 108.3 & {$[74.5]$} & 0.0001 \\
\hline Percentage of patients in foster care, ${ }^{\mathrm{c}}$ mean $[ \pm \mathrm{SD}]$ & 9.1 & [11.8] & 15.9 & {$[17.1]$} & 0.001 \\
\hline Percentage of patients using antipsychotics, ${ }^{\mathrm{a}}$ mean $[ \pm \mathrm{SD}]$ & 27.4 & [26.5] & 35.0 & [24.4] & 0.054 \\
\hline \multicolumn{6}{|l|}{ Proportion of time spent in, ${ }^{\mathrm{c}}$ mean $[ \pm \mathrm{SD}]$} \\
\hline Inpatient care & 6.4 & [10.7] & 14.8 & [18.9] & 0.0001 \\
\hline Outpatient care & 92.0 & [12.1] & 80.0 & {$[21.7]$} & 0.0001 \\
\hline Administration & 1.2 & {$[2.6]$} & 2.7 & {$[4.8]$} & 0.004 \\
\hline Teaching/research & 0.5 & [1.7] & 2.5 & {$[6.5]$} & 0.001 \\
\hline \multicolumn{6}{|l|}{ Proportion of patients diagnosed with, ${ }^{\mathrm{c}}$ mean $[ \pm \mathrm{SD}]$} \\
\hline Psychosis & 10.8 & [12.6] & 18.3 & [16.6] & 0.001 \\
\hline Bipolar disorder & 17.7 & [16.2] & 23.2 & {$[13.0]$} & 0.021 \\
\hline Conduct disorder & 29.5 & [27.0] & 20.5 & [14.6] & 0.013 \\
\hline Autism & 11.9 & [13.4] & 13.6 & [11.9] & 0.398 \\
\hline \multicolumn{6}{|l|}{ Proportion of age groups, ${ }^{\mathrm{c}}$ mean $[ \pm$ SD] } \\
\hline 5 years and under & 4.0 & {$[5.7]$} & 4.6 & {$[7.8]$} & 0.562 \\
\hline $6-12$ years & 8.5 & {$[8.2]$} & 13.7 & [14.1] & 0.002 \\
\hline $13-17$ years & 15.8 & [11.8] & 18.0 & [10.9] & 0.205 \\
\hline 18 years and over & 71.7 & {$[21.5]$} & 63.8 & {$[27.7]$} & 0.030 \\
\hline
\end{tabular}




\begin{tabular}{|c|c|c|c|c|c|c|c|}
\hline \multirow[b]{3}{*}{ Treatment } & \multicolumn{6}{|c|}{ Physician Specialty } & \multirow[b]{3}{*}{$P$ Value } \\
\hline & \multicolumn{3}{|c|}{ Primary Care Provider } & \multicolumn{3}{|c|}{ Psychiatrist } & \\
\hline & $\mathrm{N}^{\mathrm{a}}$ & \multicolumn{2}{|c|}{$\%(n)$} & $\mathrm{N}^{\mathrm{a}}$ & \multicolumn{2}{|c|}{$\%(n)$} & \\
\hline \multicolumn{8}{|c|}{ Second-generation antipsychotics } \\
\hline 5 years and under & 424 & 46.0 & (195) & 221 & 74.7 & $(165)$ & 0.0001 \\
\hline $6-12$ years & 479 & 67.2 & $(322)$ & 227 & 91.2 & $(207)$ & 0.0001 \\
\hline $13-17$ years & 387 & 78.3 & $(303)$ & 192 & 94.8 & $(182)$ & 0.0001 \\
\hline All age groups & 1,290 & 63.6 & $(820)$ & 640 & 86.6 & $(554)$ & 0.0001 \\
\hline \multicolumn{8}{|c|}{ Antipsychotic polypharmacy } \\
\hline 5 years an under & 424 & 11.5 & $(49)$ & 221 & 33.5 & $(74)$ & $<0.005$ \\
\hline $6-12$ years & 479 & 25.0 & $(120)$ & 227 & 43.2 & (98) & $<0.005$ \\
\hline 13-17 years & 387 & 32.8 & $(127)$ & 192 & 50.5 & (97) & $<0.005$ \\
\hline All age groups & 1,290 & 22.9 & $(296)$ & 640 & 42.0 & $(269)$ & $<0.005$ \\
\hline \multicolumn{8}{|c|}{ Other pharmaceutical treatment } \\
\hline 5 years and under & 424 & 30.4 & $(129)$ & 221 & 31.7 & $(70)$ & 0.744 \\
\hline $6-12$ years & 479 & 45.5 & $(218)$ & 227 & 40.5 & $(92)$ & 0.213 \\
\hline $13-17$ years & 387 & 46.0 & $(178)$ & 192 & 41.7 & $(80)$ & 0.324 \\
\hline All age groups & 1,290 & 40.7 & $(525)$ & 640 & 37.8 & $(242)$ & 0.223 \\
\hline \multicolumn{8}{|c|}{ Psychosocial treatment } \\
\hline 5 years and under & 424 & 38.9 & $(165)$ & 221 & 60.2 & $(133)$ & $<0.005$ \\
\hline $6-12$ years & 479 & 46.3 & $(222)$ & 227 & 54.2 & (123) & 0.052 \\
\hline 13-17 years & 387 & 48.3 & $(187)$ & 192 & 52.1 & $(100)$ & 0.394 \\
\hline All age groups & 1,290 & 44.5 & $(574)$ & 640 & 55.6 & $(356)$ & $<0.005$ \\
\hline \multicolumn{8}{|c|}{ Referral to another physician } \\
\hline 5 years and under & 424 & 59.9 & $(254)$ & 221 & 23.5 & $(52)$ & $<0.005$ \\
\hline $6-12$ years & 479 & 47.8 & $(229)$ & 227 & 15.4 & $(35)$ & $<0.005$ \\
\hline $13-17$ years & 387 & 42.6 & $(165)$ & 192 & 10.4 & $(20)$ & $<0.005$ \\
\hline All age groups & 1,290 & 50.2 & $(648)$ & 640 & 16.7 & $(107)$ & $<0.005$ \\
\hline
\end{tabular}

as likely, and those with a moderate condition were 1.10 (95\% $\mathrm{CI}=1.05-1.17)$ times as likely, to receive second-generation antipsychotics when compared with mild patients. When compared with the aged 15 years patient profile, the probabilities of receiving a treatment recommendation for second-generation antipsychotics were $25 \%(\mathrm{RR}=0.75 ; 95 \% \mathrm{CI}=0.68-0.84)$ and $6 \%(\mathrm{RR}=0.94 ; 95 \% \mathrm{CI}=0.91-0.99)$ lower for the profiles of a child aged 4 and 10 years, respectively.

Primary care providers were about twice as likely to recommend second-generation antipsychotics if they believed the use of second-generation antipsychotics was a labeled indication ( $\mathrm{RR}=2.16 ; 95 \% \mathrm{CI}=1.56-2.98)$ or a medically accepted use ( $\mathrm{RR}=1.88 ; 95 \% \mathrm{CI}=1.33-2.67$ ) when compared with physicians who believed there was no evidence available. This effect was not found to be significant among psychiatrists, although the RRs indicate that psychiatrists also seemed somewhat more likely to prescribe second-generation antipsychotics if they believed there was evidence supporting use. Similarly, primary care providers, but not psychiatrists, were significantly influenced by patient WBC counts. Patients with healthy WBC counts were 1.11 (95\% CI=1.05-1.17) times as likely to receive a second-generation antipsychotic compared with those who had low WBC counts from primary care providers.

\section{Discussion}

This study uses survey research methods to study approaches used by physicians for the treatment of mental health in children. Many of the factors evaluated are not available in administrative claims datasets, thus, providing unique contribution to this literature. The results of this study demonstrate that psychiatrists were more likely than primary care providers to recommend second-generation antipsychotics for children with psychosis. This finding is similar to that of Cooper et al. (2006), who found that increase in frequency of antipsychotic use by "mental health providers" was more than twice the increase seen in "non-mental health providers."16 Documented expert interviews corroborate the hypothesis that most primary care providers are likely to refer patients as soon as psychotic symptoms are identified. ${ }^{23}$ Since a large percentage of children with mental health problems are treated by primary 
Factors Influencing the Use of Second-Generation Antipsychotics in Children with Psychosis

TABLE 4 Comparison of Factors Influencing Physician Prescription of Second-Generation Antipsychotics

\begin{tabular}{|c|c|c|c|c|c|c|}
\hline \multirow[b]{2}{*}{ Characteristics } & \multicolumn{3}{|c|}{ Primary Care Provider ${ }^{\mathrm{a}, \mathrm{b}}(\mathrm{n}=129)$} & \multicolumn{3}{|c|}{ Psychiatrist $^{\mathrm{a}, \mathrm{b}}(\mathrm{n}=64)$} \\
\hline & RR & $95 \% \mathrm{CI}$ & $P$ Value & RR & $95 \% \mathrm{CI}$ & $P$ Value \\
\hline \multicolumn{7}{|l|}{ Physician Factors } \\
\hline \multicolumn{7}{|l|}{ Physician's belief about evidence supporting use } \\
\hline Labeled indication & 2.16 & $1.56-2.98$ & $<0.001$ & 1.11 & $0.93-1.33$ & 0.230 \\
\hline Medically accepted use & 1.88 & $1.33-2.67$ & $<0.001$ & 1.11 & $0.93-1.32$ & 0.240 \\
\hline \multicolumn{7}{|l|}{ Physician race } \\
\hline Asian American & 1.07 & $0.95-1.20$ & 0.270 & 1.07 & $0.95-1.20$ & 0.270 \\
\hline Caucasian & 0.98 & $0.88-1.10$ & 0.773 & 0.98 & $0.88-1.10$ & 0.773 \\
\hline Percentage of patients diagnosed with psychosis & 1.00 & $0.99-1.00$ & 0.273 & 1.00 & $0.99-1.00$ & 0.273 \\
\hline $\begin{array}{l}\text { Percentage of patients using second-generation } \\
\text { antipsychotics }\end{array}$ & 1.00 & $1.00-1.00$ & 0.031 & 1.00 & $1.00-1.00$ & 0.031 \\
\hline Years spent in active practice & 1.01 & $1.00-1.01$ & 0.170 & 1.01 & $1.00-1.01$ & 0.170 \\
\hline \multicolumn{7}{|l|}{ Patient Factors } \\
\hline \multicolumn{7}{|l|}{ Patient severity } \\
\hline Severe & 1.11 & $1.04-1.18$ & $<0.001$ & 1.11 & $1.04-1.18$ & $<0.001$ \\
\hline Moderate & 1.10 & $1.05-1.17$ & $<0.001$ & 1.10 & $1.05-1.17$ & $<0.001$ \\
\hline \multicolumn{7}{|l|}{ Patient age } \\
\hline 4 years & 0.75 & $0.68-0.84$ & $<0.001$ & 0.75 & $0.68-0.84$ & $<0.001$ \\
\hline 10 years & 0.94 & $0.91-0.99$ & 0.016 & 0.94 & $0.91-0.99$ & 0.016 \\
\hline Patient WBC count (normal range) & 1.11 & $1.05-1.17$ & $<0.001$ & 1.00 & $0.96-1.04$ & 0.877 \\
\hline Patient ANC (normal range) & 0.99 & $0.96-1.03$ & 0.776 & 0.99 & $0.96-1.03$ & 0.776 \\
\hline \multicolumn{7}{|c|}{$\begin{array}{l}\text { Note: Reference categories: Evidence supporting use-No evidence available; Physician race-Other; Patient severity-Mild; Patient age-15 years; Patient WBC count-Low } \\
\text { WBC count; Patient ANC-Low ANC. Dependent variable: whether a second-generation antipsychotic was prescribed. }\end{array}$} \\
\hline \multicolumn{7}{|c|}{$\begin{array}{l}\text { a Separate RRs and } 95 \% \text { CIs are provided for primary care providers and psychiatrists wherever the interaction between physician specialty and the predictor is significant } \\
\text { at the } 0.05 \text { level (belief about evidence supporting use and patient WBC count). Wherever the interaction is not significant, the same RR, } 95 \% \text { CI, and P value have been } \\
\text { shown under both columns. }\end{array}$} \\
\hline \multicolumn{7}{|c|}{$\begin{array}{l}\text { bThe effect of physician specialty, while not presented in this table, was also included in the model. This effect comparing primary care providers and psychiatrists in this } \\
\text { model is conditional on patient WBC count being low and no evidence available supporting use (i.e., the reference categories for the variables involved in the interaction). } \\
\text { For ease of interpretation it was excluded from the table. }\end{array}$} \\
\hline \multicolumn{7}{|c|}{$\begin{array}{l}\text { 'For percentage of patients using second-generation antipsychotics, the } 95 \% \mathrm{CI} \text { does not include } 1 \mathrm{w} \\
\text { ANC=absolute neutrophil count; } C I=\text { confidence interval; } R R=\text { risk ratio; } W B C=\text { white blood cell. }\end{array}$} \\
\hline
\end{tabular}

care providers, it is important to understand the differences between them and psychiatrists and how they might affect the quality of care received by children.

\section{Patient Characteristics}

Patient characteristics found to significantly predict recommendation of second-generation antipsychotics included age, WBC count, and disease severity. In line with expectations, patients were more likely to be recommended second-generation antipsychotics when their disease was severe or moderate, in comparison with mild severity. ${ }^{24}$ Physicians were less likely to recommend second-generation antipsychotics to children aged 4 years and 10 years when compared with children aged 15 years. Pathak et al. (2010) also found that use of second-generation antipsychotics increases with increase in patient age. ${ }^{1}$

The significance of WBC count in treating children with mental health disorders is not very common in published literature. However, WBC values are suggested for constant monitoring if the patient is using clozapine, which has a black box warning listed for agranulocytosis. ${ }^{25,26}$ While this effect does not seem to exist across all antipsychotics, it still seems to drive prescribing behavior among primary care providers. In this study, it was not possible to determine if the significance of WBC count could be attributed solely to the presence of clozapine among the possible treatment options.

Not all second-generation antipsychotics have labeled indications for use in young children with psychosis; therefore, the level of concern on the part of parents or guardians when providing consent for their use was hypothesized to be a factor influencing decisions about prescribing second-generation antipsychotics. ${ }^{8}$ However, parental concern and whether a patient was a foster child were not found to be significant predictors. These factors failed to meet the alpha of 0.1 in the initial models for each physician type and thus were not included in the final models. Studies that highlight the disproportionately high use of antipsychotics in foster children suggest that this might be a result of greater exposure to trauma, frequent changes in foster placement, and varying state oversight policies. ${ }^{8,9,27}$ The finding that physicians are no more likely to recommend these drugs to foster children, after 
controlling for other factors, provides evidence that the increased use of antipsychotics in foster children with psychosis may be driven more by clinical factors than foster status of the child. This is consistent with previous research documenting that the more frequent use of antipsychotics in foster children appears to be related to higher needs more so than disparities in care. ${ }^{9}$ A similar positive finding in this study is the nonsignificance of "parental concern." The nonsignificance of social factors reinforces the belief that physician prescription decisions for treatment of psychosis in children are driven more by objective clinical criteria.

Patient sex, race, BMI, puberty status, alcohol use, and blood glucose levels also did not meet the criteria for inclusion in the models for each physician type. The nonsignificant effect of BMI is particularly concerning because it appears that physicians do not take into account metabolic functions before recommending second-generation antipsychotics. In addition to the quality measures that deal with metabolic monitoring, the monitoring of a patient's BMI is recommended by several guidelines. ${ }^{25,27-30}$

\section{Physician Characteristics}

The most important physician characteristic influencing prescribing behavior was specialty. Cooper et al. found similar results in their study on trends in the prescription of antipsychotics using data from the National Ambulatory Medical Care Survey and the National Hospital Ambulatory Medical Care Survey. ${ }^{16}$ Belief about evidence supporting use of second-generation antipsychotics was found to be a significant predictor among primary care providers but not among psychiatrists. It is possible that the lack of significance among psychiatrists was a function of the sample size in that group, but the direction of the effect was similar in both groups of physicians.

The finding with the most direct impact on managed care was physician awareness of evidence supporting use of secondgeneration antipsychotics in children. A substantial proportion of physicians believed second-generation antipsychotics were a labeled or medically accepted use among children aged 5 years and under (Table 2), while almost none of these drugs actually had any evidence to support that use. This behavior of off-label prescribing in mental health providers is not unexpected and has been demonstrated before. ${ }^{1}$ These numbers suggest that physician education regarding second-generation antipsychotic use is the utmost priority. Further, the development of treatment guidelines might help improve prescription behavior.

In line with expectations, physicians whose clinical practice had a greater proportion of children using second-generation antipsychotics were more comfortable recommending these drugs in the simulation experiment. This effect did not vary significantly by physician specialty. Primary care providers recommended multiple second-generation antipsychotics in $23 \%$ of the profiles, and psychiatrists did so in $42 \%$ of the pro- files, which is higher than that observed even in elderly populations in previous research. ${ }^{31}$ Antipsychotic polypharmacy is not recommended in any age group because of the increase in risk of metabolic syndrome. ${ }^{32}$ Use of multiple antipsychotics is also one of the HEDIS measures for children. Only about $50 \%$ of the patients were recommended psychosocial therapy. This finding, while not unprecedented, ${ }^{33}$ is very concerning because the National Collaborative for Innovation in Quality Measurement identified access to psychosocial care as a "needed service associated with medication use,"34 and use of psychosocial therapy is also a HEDIS measure used to evaluate health plans.

\section{Limitations}

This study provides valuable insights into decisions related to prescribing second-generation antipsychotics to children. As with any study, however, there are limitations that need to be considered. A summary of the study results was offered as the only incentive for participation. There exists a potential risk for nonresponse bias. The sample obtained was conveniently sampled and somewhat skewed in terms of the distribution for race (majority Caucasians and Asian Americans) and gender (majority male), which could further limit generalizability of the findings. The sample size, while sufficient, was somewhat small, especially for psychiatrists. This could have resulted in missing effects that might have been significant predictors of prescribing decisions. The location of a provider's practice (urban vs. rural) could have also influenced prescribing practice. However, this information was not collected during this study. Physician treatment recommendations are also influenced by insurance restrictions. However, this study did not account for such effects. This study focused on patients diagnosed with psychosis. Generalizations to other mental health conditions in children must be made with caution. Respondent comfort and experience with use of second-generation antipsychotics might have influenced treatment recommendations, especially among primary care practitioners. However, respondents were not screened based on the number of patients with psychosis. The use of vignettes to simulate patients carries some drawbacks. Respondents were not able to acquire additional information that they may have felt was needed. While researchers have demonstrated that vignettes offer adequate validity in measuring quality of care, it should be noted that actual treatment decisions made by physicians might be different. ${ }^{35-37}$ Treatment patterns for the profiles may also have been influenced by social desirability.

\section{Conclusions}

This study tested the factors influencing the prescription of second-generation antipsychotics among children with psychosis by presenting patient profiles with factors of interest. The analysis provided insights in 5 main areas: (1) psychiatrists 
were more willing to recommend second-generation antipsychotics, than general practitioners; (2) older children were more likely to receive these medications than younger ones; (3) there was no difference in prescription rates between children in foster care and those who were not; (4) parental concerns regarding the use of antipsychotics did not appear to have influenced physician decisions; and most significantly, (5) physicians were more likely to recommend second-generation antipsychotics if they thought there was evidence to support their use. Findings regarding patient BMI, recommendations of psychosocial therapy, belief about evidence supporting use, and antipsychotic polypharmacy provide insight into physician behaviors that may have serious effects on managed care quality ratings. These results can help managed care programs gain a better understanding of this therapeutic area and plan appropriate education and other interventions to ensure quality care.

\section{Authors}

SUJITH RAMACHANDRAN, MS, PhD Candidate; BENJAMIN F. BANAHAN III, PhD; JOHN P. BENTLEY, PhD; and DONNA S. WEST-STRUM, PhD, University of Mississippi, University, Mississippi. AMIT S. PATEL, PhD, Medical Marketing Economics, Oxford, Mississippi.

AUTHOR CORRESPONDENCE: Sujith Ramachandran, MS, PhD Candidate, 223B Faser Hall, University of Mississippi, University, MS 38677. E-mail: sramacha@go.olemiss.edu.

\section{DISCLOSURES}

No outside funding supported this research. Bentley reports the receipt of grants from PQA and the NACDS Foundation. Patel is employed by Medical Marketing Economics. The authors report no other conflicting interests, potential or otherwise.

Study concept and design were contributed by Ramachandran, Banahan, West-Strum, and Bentley. Ramachandran, Banahan, and Patel collected data; data interpretation was performed primarily by Ramachandran, Banahan, and Patel, along with Bentley and West-Strum. The manuscript was primarily written by Ramachandran, along with Banahan and Bentley, and revised by Banahan, Bentley, West-Strum, and Patel.

\section{ACKNOWLEDGMENTS}

The authors thank Reckner Healthcare for programming and fielding the study.

\section{REFERENCES}

1. Pathak P, West D, Martin B, et al. Evidence-based use of second-generation antipsychotics in a state Medicaid pediatric population, 2001-2005. Psychiatr Serv. 2010;61(2):123-29.

2. Alexander GC, Gallagher SA, Mascola A, et al. Increasing off-label use of antipsychotic medications in the United States, 1995-2008.

Pharmacoepidemiol Drug Saf. 2011;20(2):177-84.
3. Vitiello B, Correll C, van Zwieten-Boot B, et al. Antipsychotics in children and adolescents: increasing use, evidence for efficacy and safety concerns. Eur Neuropsychopharmacol. 2009;19(9):629-35.

4. McIntyre RS, Jerrell JM. Metabolic and cardiovascular adverse events associated with antipsychotic treatment in children and adolescents. Arch Pediatr Adolesc Med. 2008;162(10):929-35.

5. Fedorowicz VJ, Fombonne E. Metabolic side effects of atypical antipsychotics in children: a literature review. J Psychopharmacol. 2005;19(5):533-50.

6. Kumra S, Oberstar JV, Sikich L, et al. Efficacy and tolerability of secondgeneration antipsychotics in children and adolescents with schizophrenia. Schizophr Bull. 2008;34(1):60-71.

7. Surles RC. Atypical antipsychotics: considerations for Medicaid coverage. Am J Manag Care. 2005;11(8 Suppl):S248-53.

8. Strawbridge KE. Children are crying: the need for change in Florida's management of psychotropic medication to foster children. UC Davis J Juv Law Pol. 2011;15:247-96.

9. Government Accountability Office. Foster children: HHS guidance could help states improve oversight of psychotropic prescriptions. GAO-12-

270T. Washington, DC. December 2011. Available at: http://www.gao.gov/ assets/590/586570.pdf. Accessed June 24, 2016.

10. Sheldon GH, Hyde PS, Berwick D. Letter to state Medicaid directors. U.S. Department of Health \& Human Services. November 2011. Available at: https://www.childwelfare.gov/systemwide/mentalhealth/effectiveness/ jointlettermeds.pdf. Accessed June 24, 2016.

11. Centers for Medicare \& Medicaid Services. CMS quality strategy 2016. January 2016. Available at: https://www.cms.gov/Medicare/QualityInitiatives-Patient-Assessment-Instruments/QualityInitiativesGenInfo/ Downloads/CMS-Quality-Strategy.pdf. Accessed June 24, 2016.

12. Sullivan, Cotter and Associates. SullivanCotter releases 2014 Physician Compensation and Productivity Survey results. Business Insider. December 8, 2014. Available at: http://www.businesswire.com/news/ home/20141208005898/en/SullivanCotter-Releases-2014-PhysicianCompensation-Productivity-Survey\#.VKbOxSvF8dU. Accessed June 24, 2016.

13. National Committee for Quality Assurance. HEDIS 2016. November 2015. Available at: http://www.ncqa.org/HEDISQualityMeasurement/ HEDISMeasures/HEDIS2016.aspx. Accessed June 24, 2016.

14. Hamann J, Langer B, Leucht S, Busch R, Kissling W. Medical decision making in antipsychotic drug choice for schizophrenia. Am J Psych. 2004;161(7):1301-04.

15. Cullen KR, Kumra S, Regan J, et al. Atypical antipsychotics for treatment of schizophrenia spectrum disorders. Psychiatr Times. 2008;25(3):61.

16. Cooper WO, Arbogast PG, Ding H, Hickson GB, Fuchs DC, Ray WA. Trends in prescribing of antipsychotic medications for U.S. children. Ambul Pediatr. 2006;6(2):79-83.

17. Reckner Healthcare. Panels. Physicians \& allied healthcare. Available at: http://recknerhealthcare.com/healthcare-panels.php. Accessed July 5, 2016.

18. Mosca L, Linfante AH, Benjamin EJ, et al. National study of physician awareness and adherence to cardiovascular disease prevention guidelines. Circulation. 2005;111(4):499-510.

19. Aarons GA. Mental health provider attitudes toward adoption of evidence-based practice: The Evidence-Based Practice Attitude Scale (EBPAS). Ment Health Serv Res. 2004;6(2):61-74.

20. Aarons GA, Glisson C, Hoagwood K, Kelleher K, Landsverk J, Cafri G. Psychometric properties and US national norms of the Evidence-Based Practice Attitude Scale (EBPAS). Psychol Assess. 2010;22(2):356-65.

21. Zou GY, Donner A. Extension of the modified Poisson regression model to prospective studies with correlated binary data. Stat Methods Med Res. 2013;22(6):661-70.

22. Hosmer DW Jr, Lemeshow S. Applied Logistic Regression. New York: John Wiley \& Sons; 2004. 
23. Sussman N. In session with James D. King, MD: the status of the primary care field in relation to psychiatric care. Primary Psychiatry. May 1, 2008. Available at: http://primarypsychiatry.com/in-session-with-james-d-kingmd-the-status-of-the-primary-care-field-in-relation-to-psychiatric-care/. Accessed June 24, 2016.

24. Gleason M, Egger HL, Emslie GJ, et al. Psychopharmacological treatment for very young children: contexts and guidelines. J Am Acad Child Adolesc Psychiatry. 2007;46(12):1532-72.

25. Texas Department of Family and Protective Services. Psychotropic medication utilization parameters for foster children. December 2010. Available at: http://texaschildrenscommission.gov/media/1395/psychotropicmed.pdf. Accessed June 24, 2016.

26. San Francisco Department of Public Health. Guidelines for the use of atypical antipsychotics in adults. October 2006. Available at: http://www.sfdph.org/dph/files/CBHSdocs/MHPdocs/AtypicalAntipsychotic Guidelines102006.pdf. Accessed June 24, 2016.

27. Zito JM, Safer DJ, Sai D, et al. Psychotropic medication patterns among youth in foster care. Pediatrics. 2008;121(1):e157-63.

28. A roadmap to key pharmacologic principles in using antipsychotics. Prim Care Companion J Clin Psychiatry. 2007;9(6):444-54. Available at: http:// www.ncbi.nlm.nih.gov/pmc/articles/PMC2139919/. Accessed June 24, 2016.

29. Teicher MH, Glod CA. Neuroleptic drugs: Indications and guidelines for their rational use in children and adolescents. J Child Adolesc Psychopharmacol. 1990;1(1):33-56.
30. Varley CK, McClellan J. Implications of marked weight gain associated with atypical antipsychotic medications in children and adolescents. J Am Med Assoc. 2009;302(16):1811-12.

31. Kogut SJ, Yam F, Dufresne R. Prescribing of antipsychotic medication in a Medicaid population: use of polytherapy and off-label dosages.

J Manag Care Pharm. 2005;11(1):17-24. Available at: http://www.jmcp.org/ doi/10.18553/jmcp.2005.11.1.17.

32. Correll CU, Frederickson AM, Kane JM, Manu P. Does antipsychotic polypharmacy increase the risk for metabolic syndrome? Schizophr Res. 2007:89(1):91-100.

33. Olfson, M, Crystal S, Huang C, Gerhard T. Trends in antipsychotic drug use by very young, privately insured children. J Am Acad Child Adolesc Psychiatry. 2010;49(1):13-23.

34. National Collaborative for Innovation of Quality. Antipyschotic medication use measures for children and adolescents. Draft document for NCINQ public comment. May 17, 2013. Available at: http://www.chcs.org/media/ NCINQ_2013_Public_Comment_4-30-13.pdf. Accessed June 24, 2016.

35. Dresselhaus TR, Peabody JW, Lee M, Wang MM, Luck J. Measuring compliance with preventive care guidelines: standardized patients, clinical vignettes, and the medical record. J Gen Intern Med. 2000;15(11):782-88.

36. Peabody JW, Luck J, Glassman P, et al. Measuring the quality of physician practice by using clinical vignettes: a prospective validation study. Ann Intern Med. 2004;141(10):771-80.

37. Peabody JW, Luck J, Glassman P, et al. Comparison of vignettes, standardized patients, and chart abstraction: a prospective validation study of 3 methods for measuring quality. JAMA. 2000;283(13):1715-22. 


\section{APPENDIX Sample Patient Profile}

(102) Elizabeth:

Doctor, please assume that Elizabeth is a patient you have newly diagnosed with mild psychosis. Her history and your current evaluation notes are summarized below.

\begin{tabular}{l|l|l}
\hline Demographics & \multicolumn{1}{|c}{ Lab values } & \multicolumn{1}{c}{ Symptoms } \\
\hline Age: 15 & WBC: 7300 (Normal) & $\begin{array}{l}\text { Patient has displayed symptoms of mild psychosis: } \\
\text { Occassional uncontrollable agitation } \\
\text { ・ Minimally intrusive auditory hallucinations } \\
\text { ・ Mild lack of age-appropriate grooming }\end{array}$ \\
$\begin{array}{l}\text { Gender: Female } \\
\text { Height: } 63.7 \text { inches }\end{array}$ & ANC: 1300 (Low) & \\
$\begin{array}{l}\text { Weight: } 119.5 \text { pounds } \\
\text { BMI } 20.7 \text { (Normal) } \\
\text { Pubescent }\end{array}$ & Fasting glucose: $85 \mathrm{mg} / \mathrm{dL}$ & \\
Caucasian & & \\
\hline
\end{tabular}

The patient's diagnosis is consistent with family history. You have informed the parent about the use of atypical antipsychotics. The patient can afford her drugs.

During the visit you determine that:

- The parent is willing to sign an informed consent and hasn't expressed any concerns about the use of antipsychotics.

- The patient has no history of alcohol abuse.

- The parent mentions that the patient takes his medications on time.

Treatment options: (Please check all that apply)

$\begin{array}{ll}\text { Atypical Antipsychotics } & \text { Anti-convulsants } \\ \square \text { Aripiprazole (Abilify) } & \square \text { Lithium (Lithobid, generic) } \\ \square \text { Asenapine (Saphiris) } & \square \text { Alpha agonists } \\ \square \text { Clozapine (Clozaril, generic) } & \square \text { Other } \\ \square \text { Iloperidone (Fanapt) } & \\ \square \text { Lurasidone (Latuda) } & \square \text { Anti-depressants } \\ \square \text { Olanzapine (Zyprexa, Zyprexa Relprevv, generic) } & \square \text { Anxiolytics } \\ \square \text { Olanzapine \& Fluoxetine (Symbyax, generic) } & \square \text { Mood stabilizers } \\ \square \text { Paliperidone (Invega, Invega Sustena) } & \square \text { Stimulants } \\ \square \text { Quetiapine (Seroquel, Seroquel XR, generic) } & \square \text { Other (Please specify } \\ \square \text { Risperidone (Risperidal, Risperidal Consta, generic) } & \square \text { Psychosocial Intervention } \\ \square \text { Ziprasidone (Geodon, generic) } & \square \text { Refer to another physician with experience in dealing with pediatric } \\ & \text { mental health } \\ \text { Conventional Antipsychotics } & \square \text { Refer to non-medical practitioner } \\ \square \text { Perphenazine (Trilafon, generic) } & \square \text { Other non-pharmaceutical treatment } \\ \square \text { Chlorpromazine (generic) } & \\ \square \text { Others } & \end{array}$

